ÉGYPTE

monde arabe

\section{Égypte/Monde arabe}

$10 \mid 2013$

Les élections de la révolution (2011-2012)

\title{
Les élections législatives de 2011 à Port-Saïd
}

\section{Fayçal Homsy}

\section{OpenEdition}

Journals

Édition électronique

URL : https://journals.openedition.org/ema/3166

DOI : 10.4000/ema.3166

ISSN : 2090-7273

\section{Éditeur}

CEDEJ - Centre d'études et de documentation économiques juridiques et sociales

\section{Édition imprimée}

Pagination : 187-202

ISBN : 978-2-905838-81-0

ISSN : 1110-5097

\section{Référence électronique}

Fayçal Homsy, «Les élections législatives de 2011 à Port-Saïd », Égypte/Monde arabe [En ligne], 10 | 2013, mis en ligne le 10 février 2014, consulté le 07 juillet 2022. URL : http://journals.openedition.org/ ema/3166 ; DOl : https://doi.org/10.4000/ema.3166

Ce document a été généré automatiquement le 7 juillet 2022.

Tous droits réservés 


\title{
Les élections législatives de 2011 à Port-Saïd
}

\author{
Fayçal Homsy
}

1 Port-Saïd fut créé en 1859 sous le règne du Khédive Saïd. La ville est située sur un terrain gagné sur le Lac Manzala au sud et sur la Mer méditerranée au nord alors que le canal de Suez, achevé en 1869, borde la ville à l'est. Port-Saïd, qui compte près de 600000 habitants, est intrinsèquement lié à la vie du canal, point de passage stratégique $\mathrm{du}$ commerce mondial. La ville reste marquée par sa configuration d'origine, avec une division encore flagrante entre le quartier des étrangers et le quartier arabe (ces dénominations sont d'ailleurs toujours utilisées).

2 Port-Saïd a entretenu une relation conflictuelle avec le régime de Moubarak, en protestant contre les tentatives répétées du Caire d'annuler son statut de zone franche, $\mathrm{du}$ fait, selon la légende, de la haine que l'ex-président vouerait à Port-Saïd depuis ce qui fut présenté comme une tentative d'assassinat lors de son passage dans la ville le 6 septembre 1999. Cette version des faits serait selon les habitants un mensonge, l'homme s'étant selon eux approché du convoi présidentiel pour transmettre une liste de requêtes, avant de se faire tuer par le service de protection du raïs. C'est cette histoire qui est racontée aux enfants et aux visiteurs.

3 Cependant Port-Saïd a aussi profité de la nouvelle politique économique de libéralisation et de la volonté des gouvernements successifs d'en faire un hub régional $\mathrm{du}$ commerce maritime mondial. Les usines du $\mathrm{QUIZ}^{1}$, notamment de textile, le tourisme, les services maritimes sont parmi les activités économiques les plus importantes de la ville, tout comme le commerce de produits importés sans droits de douanes. Ainsi, la ville est logiquement dépendante de la stabilité politique et économique du pays.

4 La mobilisation sociale à Port-Saïd lors de la révolution fut timide, bien que des manifestations aient eu lieu et que des bus d'habitants de la ville aient fait le voyage tous les vendredis jusqu'à la place Tahrir. 
Résultats des élections législatives de novembre 2011 au majlis al-cha'b, la chambre basse

\begin{tabular}{|c|c|c|c|}
\hline $\begin{array}{l}\text { Port-Saïd (un seul district }-6 \\
\text { sièges) }\end{array}$ & $\begin{array}{l}\text { Nombres de } \\
\text { votes }\end{array}$ & \% de votes & sièges \\
\hline Listes & & & 4 \\
\hline Liberté et Justice & 95532 & 32,66 & 1 \\
\hline Al-Nûr & 61136 & 20,69 & 1 \\
\hline Al-Wafd & 41059 & 13,89 & 1 \\
\hline Al-Wasat & 38080 & 12,88 & 1 \\
\hline Le Bloc égyptien & 28510 & 9,65 & 0 \\
\hline Le Parti national & 6681 & 2,26 & 0 \\
\hline L'Union arabe & 5704 & 1,93 & 0 \\
\hline La Révolution continue & 4388 & 1,85 & 0 \\
\hline La Révolution égyptienne & 4388 & 1,48 & 0 \\
\hline \multicolumn{4}{|l|}{ Candidatures individuelles } \\
\hline Akram Al-Chầir (Liberté et Justice) & 147,024 & $\begin{array}{ll}51 \quad \text { (victoire au } \\
\text { premier tour) }\end{array}$ & 1 \\
\hline $\begin{array}{l}\text { Al-Badrî Farghalî (Indépendant de } \\
\text { gauche)- ouvrier }\end{array}$ & 87,972 & 13 & $\begin{array}{l}1 \quad \text { (victoire au } \\
\text { second tour) }\end{array}$ \\
\hline ‘Alî Fûda (Al-Nûr) - ouvrier & 37,825 & 31 & 0 \\
\hline
\end{tabular}

$5 \quad$ L'objet de cet article est de rendre compte des logiques et motivations expliquant les résultats des élections législatives de novembre 2011 (premières élections après la chute du régime de Hosni Moubarak) à Port-Saïd, véritable ville-circonscription.

6 Ainsi sur la base d'entretiens avec divers candidats ou responsables politiques de PortSaïd, et sur la base de discussions avec les habitants, trois principaux critères semblent expliquer le choix des électeurs : l'implantation locale, l'intégrité morale et la religion du candidat.

7 Nous montrerons dans cet article comment ces trois critères sont mis en avant dans le discours des électeurs et comment ils expliquent les résultats des élections. 


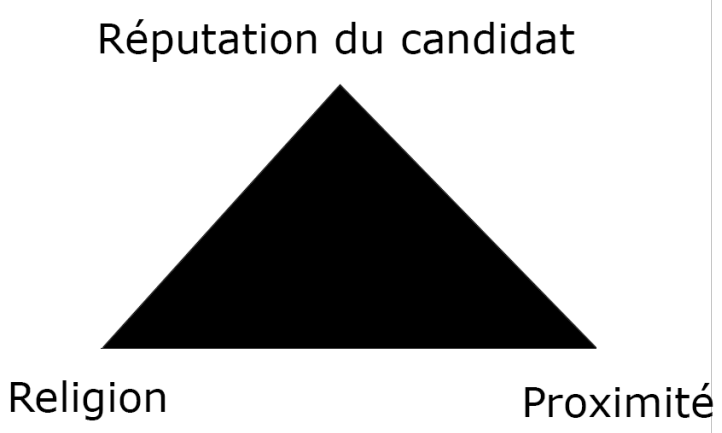

\section{À la recherche du responsable politique vertueux : le succès des médecins islamistes}

8 À Port-Saï, l'assurance des islamistes était palpable. Leur campagne fut humble, sans grands rassemblements publics, sinon des jeux de connaissance sur le Coran organisés pour les enfants à la plage. Le responsable politique du parti des Frères musulmans, Galâl Samîr, affirmait ainsi :

« Nous prévoyons pour notre parti et ses alliés de l'Alliance démocratique de 40 à $50 \%$ des suffrages. Pour toutes les mouvances islamistes, ce sera sûrement aux environ de 60 »

9 Au regard de la rapide visibilité politique des entrepreneurs sociaux de la confrérie, il semble que les islamistes aient bien réussi à capitaliser sur le terrain politique ce qu'ils ont investi depuis de nombreuses années dans leurs activités caritatives, qui leur ont permis de conquérir une large assise sociale

10 Akram al-Châ'ir, candidat indépendant des Frères musulmans, ainsi que les têtes de listes islamistes sont des médecins. Leur succès n'est pas anodin. Des électeurs interrogés à la sortie des urnes ont affirmé avoir voté salafiste car la tête de liste est un "bon médecin qui fait beaucoup de khayr (faire le bien)», soit des consultations gratuites pour les pauvres. Le médecin revêt une importance capitale pour le citoyen égyptien : il est l'intellectuel affable qui paraît bon du fait de son accessibilité, pourtant normale et rentable. À l'évidence, l'échec du précédent régime à assurer un minimum de service public de santé contribue à ce succès électoral des médecins islamistes, qui personnifient par ailleurs à merveille le slogan de campagne national des Frères musulmans, «faire le bien en Égypte ».

11 La réputation de tel ou tel candidat occupe une place décisive dans les débats politiques des habitants de la ville. Le témoignage d'un jeune commerçant sympathisant islamiste, ayant un ami se présentant aux élections en indépendant, illustre assez bien cette logique :

"Mon ami bien que barbu n'a aucune chance, il se lance en politique sans avoir effectué du travail social au sein d'une association pour se faire une réputation. Personne ne le connaît !»

12 Le travail au sein d'une association caritative, professionnelle ou encore sportive est plus qu'une simple preuve de la légitimité et de l'honnêteté des intentions du candidat, il serait non seulement un moyen de se rendre visible sur le terrain, mais aussi la voie unique de sélection des représentants de la nation. 
13 Si les activités socio-caritatives sont un gage de l'honnêteté du candidat, elles représentent aussi une façon de gouverner, un programme politique fondé, non pas sur la solidarité, mais sur la générosité désintéressée des élites économiques, comme le laissent entendre les propos du candidat socialiste Al-Badrî Farghalî :

« le socialisme en Égypte en 2011 c'est la recherche de l'égalité véritable et non pas

une simple intensification de la charité religieuse ».

Dans le discours des partisans des islamistes, il ressort parfois un enthousiasme dû au fait qu'ils anticipent le règne prochain des vertueux. Leurs espérances se construisent non seulement sur la future moralité irréprochable de leurs représentants politiques, mais aussi sur le règne futur des pieuses victimes des injustices de l'ancien régime, qui accéderont enfin à la dignité.

L'idée de transformation de la société par le haut est un facteur majeur dans la décision de voter pour des candidats islamistes. La plupart des électeurs interrogés affirment ainsi que Moubarak avait réussi à pervertir un pays entier par un processus en cascade : la corruption de l'élite rejaillissait sur tous les pans de la société, permettant par exemple au fonctionnaire de demander un bakchich, car il se disait "pourquoi pas moi ? ». Ce phénomène serait selon eux réversible par l'élection à la tête du pays d'un exemple de vertu. Ce discours est représentatif d'une décision de vote qui se base sur le comportement et la moralité, et explique pourquoi même certains croyants modérés ou des personnes ne cherchant pas à vivre selon les règles du Coran, ont voté salafiste ou Frères musulmans.

16 La réputation et la popularité issues d'actions sociales au service des habitants de la circonscription, qui ont si bien réussi aux médecins islamistes de Port-Saïd, renvoie à une préoccupation plus large de l'électorat. Cette préoccupation est un quasi-réflexe du citoyen : les habitants de Port-Saïd veulent un député qui soit un produit de leur ville et qui défende leurs propres intérêts.

\section{La demande de proximité}

17 Entre enjeux nationaux et intérêts locaux, les électeurs de Port-Saïd ont fait leur choix. Le candidat s'il veut l'emporter, doit prouver son enracinement local dans son programme politique et son propre parcours. Concernant les candidats de la mouvance islamiste, la discipline de parti et la centralisation des mouvements politiques suscitent la méfiance des électeurs. Celle-ci paraît justifiée au regard de l'hésitation, lors d'un entretien, de Galâl Samîr à confirmer la prépondérance des intérêts de Port-Saïd sur le programme politique national des Frères musulmans :

«Q: Pourriez-vous défendre les intérêts des habitants de Port-Saïd y compris contre votre propre parti?

$\mathrm{R}$ : L'intérêt de Port-Saïd rejoint l'intérêt du pays "

18 Ainsi les tracts récapitulant les programmes des candidats font la part belle aux enjeux socio-économiques de la ville ou pire, embrassent l'égoïsme local. La proposition politique la plus partagée par les candidats aux législatives est la très populaire obligation pour les usines de la ville de systématiquement réserver un proportion des emplois offerts aux habitants de la ville. Port-Saïd serait victime, selon Girgis Grîs candidat sur la liste du Bloc égyptien (pourtant libéral) d'une trop forte immigration des campagnes, qui tirerait les salaires à la baisse et qui dégraderait les conditions de travail offertes : 
« il faut également s'assurer que les emplois dédiés au commerce et à l'exportation reviennent aux habitants de la ville»

Ainsi, dans les conversations des habitants, Tahrir, la Constitution et le maréchal Muhammad Husayn Tantâwî $\hat{i}^{2}$ sont bien loin. Les problèmes locaux de logements, de voirie, ou encore d'éducation sont les principaux débats animant la campagne électorale. Les candidats ont ainsi longuement insisté lors d'entretiens, sur ces différentes préoccupations des habitants :

Le débat autour de la création d'une ville nouvelle qui permettrait de répondre à la pénurie de logements et de terrains constructibles disponibles. L'affairisme immobilier étant un sport national en Égypte, cette question du logement est la préoccupation principale et favorite des habitants de la ville. Elle renvoie également à la question du mariage des jeunes de Port-Saïd, rendu difficile à cause du prix des logements. Ainsi, Mahmûd Tantâwî, candidat indépendant, affirmait que :

« la politique de développement urbain est à revoir, notamment le projet de ville nouvelle à l'est du Canal, les ingénieurs affirment que les terrains ne sont pas constructibles »

Le responsable politique des Frères musulmans à Port-Saïd, Galâl Samîr.

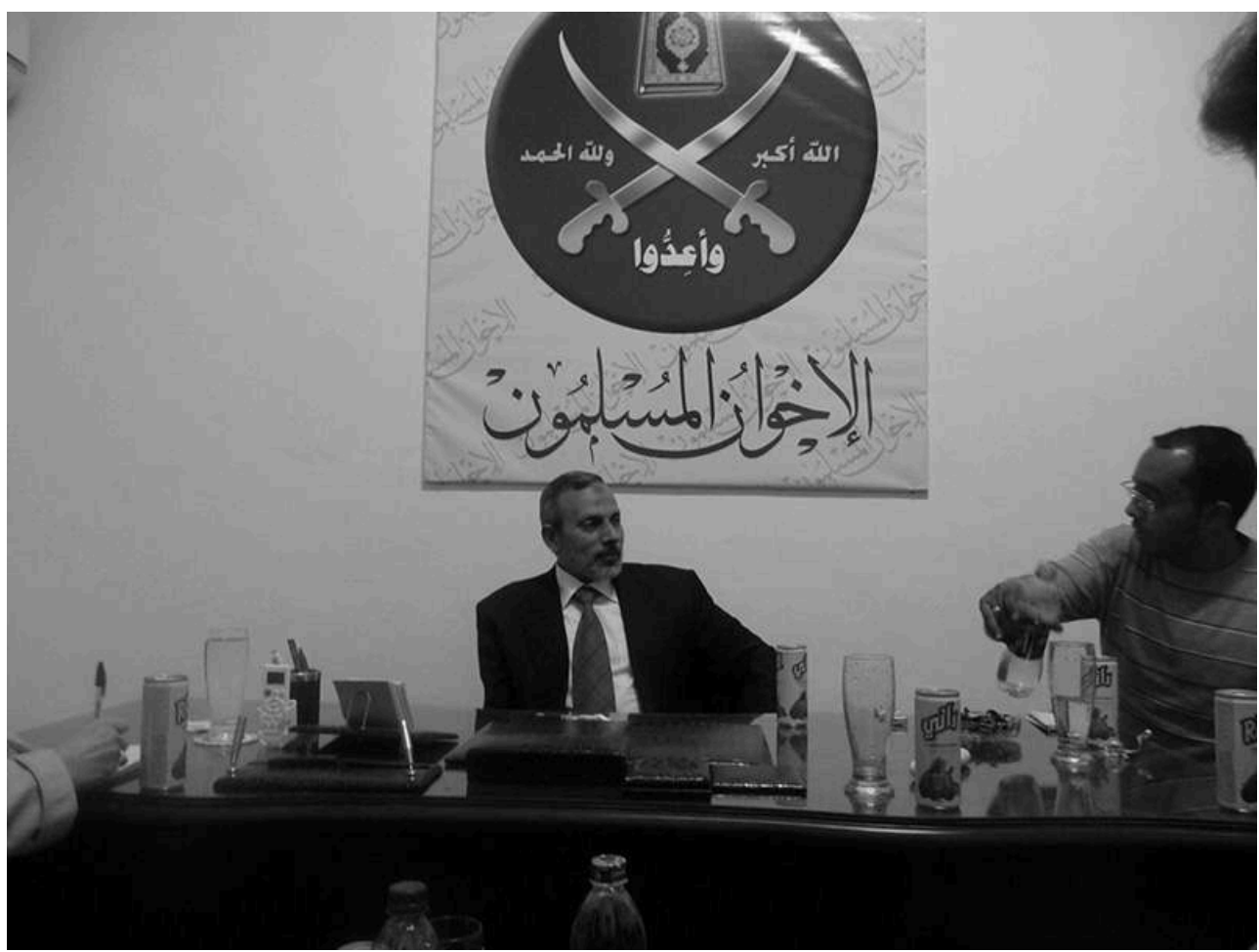

Affiches de campagne des candidats du parti des Égyptiens libres, dont Girgis Grîs et Rîhâm Sulaymân. Les seules affiches rescapées sont situées dans les quartiers riches, le portrait de la candidate sans voile et à la chevelure couleur platine a amusé les hommes de la ville et agacé les islamistes. 


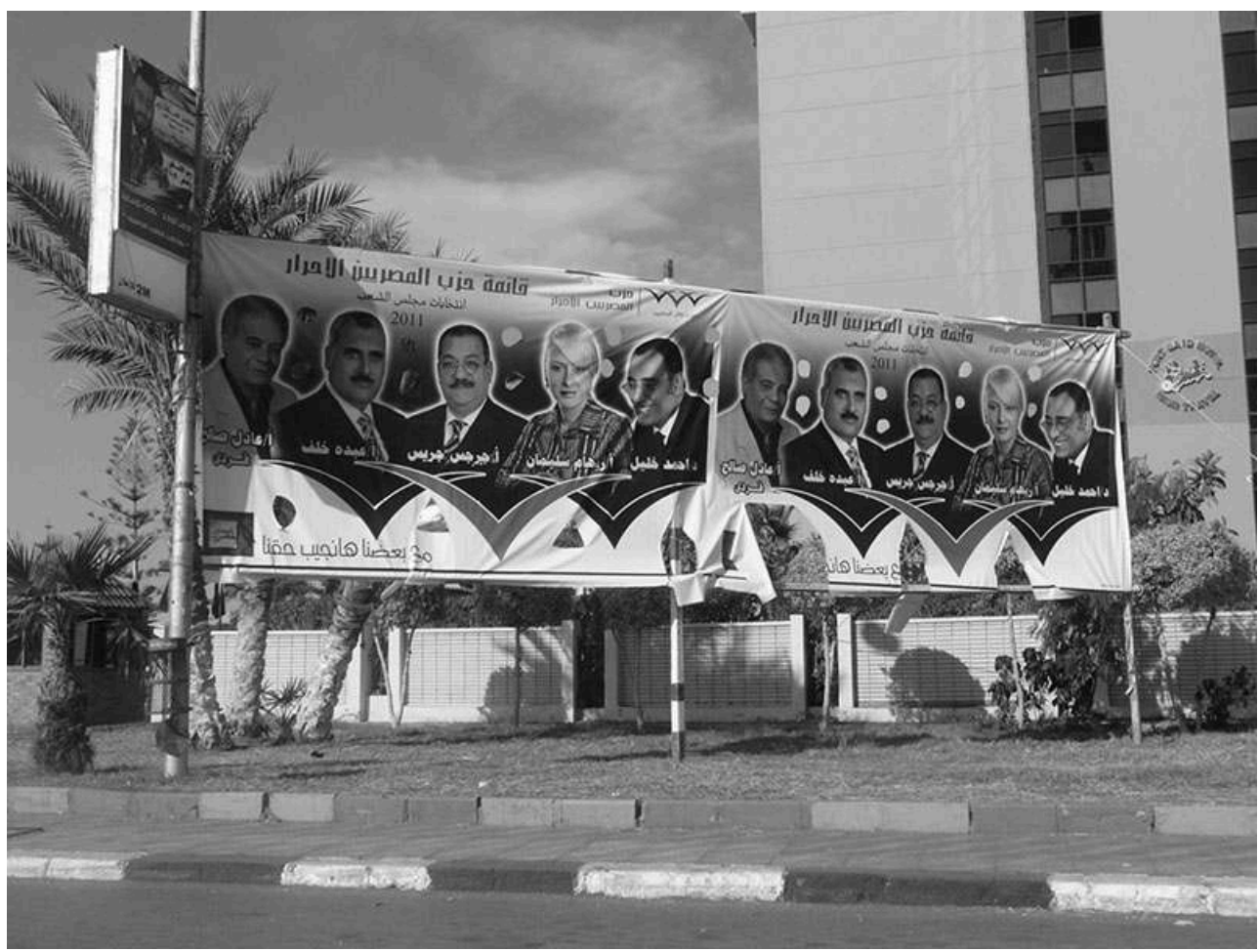
tout entière. Des rumeurs d'enlèvements ou de meurtres sont colportées dans toute la ville, l'incendie des commissariats ou d'autres bâtiments officiels et la présence d'armes à feu est désormais fréquente, du fait du retrait de la police. L'insécurité, qui menace l'activité économique, inquiète les parents et les commerçants dont certains affirment 
même qu'elle est la conséquence directe des tourments politiques et des manifestations permanentes au Caire. Cette inquiétude est à prendre en compte selon Mahmûd Tantâwî qui affirme que:

« la sécurisation du pays est primordiale pour relancer l'économie. »

Affiche de campagne d'un candidat indépendant, un supposé fulûl. Des habitants du quartier affirment vouloir voter pour lui car ils connaissaient son père qui « était très serviable. Son fils doit aussi l'être ".

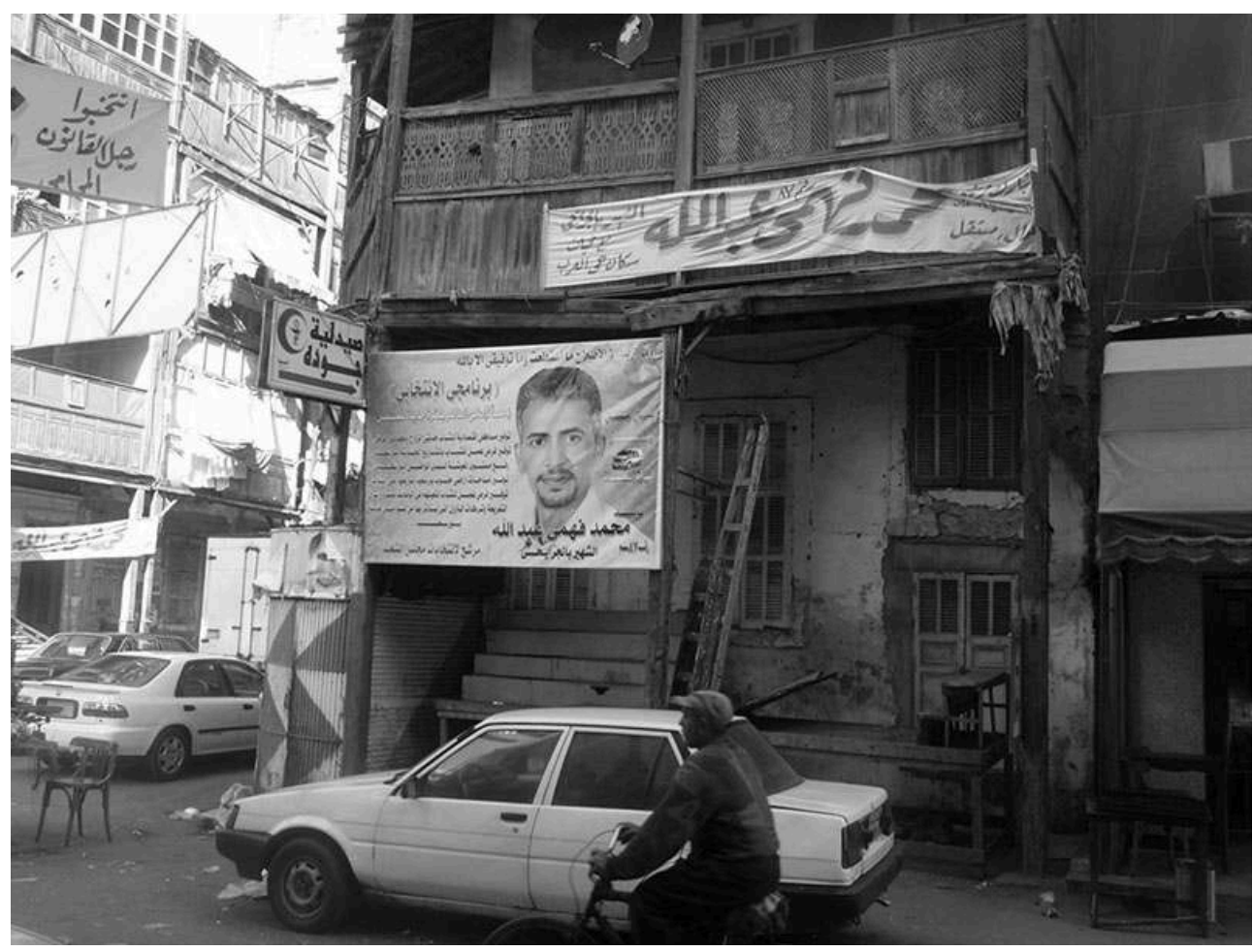


Al-Badrî Farghalî, candidat ouvrier indépendant élus après le deuxième tour, dans son QG de campagne, un kahwâ de la rue al-Talâtîn.



Candidats du parti des Égyptiens libres, Rîhâm Sulayman et Girgis Grîs souhaitent une réforme de l'appareil sécuritaire pour garantir son efficacité :

«La sécurisation entendue comme réforme et efficience de la police est primordiale pour accompagner la relance de l'économie égyptienne»

Alors que Galâl Samîr, responsable de Port-Saïd au sein des Frères musulmans répond à la question « Allez-vous tenter de préserver l'esprit de la révolution?», par :

«Les gens veulent la stabilité »

- Enfin, le travail des jeunes est également un thème majeur de cette campagne. Les candidats ont tous affirmé en entretien que créer des emplois pour la jeunesse égyptienne était la réponse logique et attendue à la révolution de janvier. Notamment Mahmûd Tantâwî, qui voit dans la lutte contre le chômage des jeunes le fondement du rôle du député :

«le futur député devra travailler sur la Constitution, il devra également essayer d'influencer le gouvernement afin d'obtenir pour sa circonscription des projets d'emploi et des programmes sociaux pour la jeunesse. Mon slogan de campagne est : « Je me rappellerai de toi ». Les causes de la révolution sont sociales »

30 Cette absence de communication sur des enjeux proches des préoccupations des habitants et sur ses attaches locales contribuent à expliquer l'échec électoral de George Ishâq. Le témoignage suivant d'un habitant de la ville illustre une opinion alors massivement partagée à Port-Saï :

«ah bon il est né ici ? Pourtant il n'a jamais vécu ici, on ne le voit pas, sauf à la télévision. Son discours est trop national. Il passe tout son temps au Caire. J’ai des amis coptes, mais lui il ne croit pas en Dieu »

31 Cette dernière partie du témoignage est représentative du troisième facteur de ces élections : le rôle de la religion. La candidature de Georges Ishâq, de religion copte et 
fondateur du mouvement Kifâya, a sans aucun doute souffert de l'absence combinée de ces deux conditions décisives pour les habitants : la proximité et la religion.

\section{Le facteur religieux à Port-Saïd : les difficultés des candidats libéraux et la méfiance des femmes envers les islamistes}

Alors que la réputation (y compris de piétée religieuse) et l'attache locale du candidat et des idées qu'il défend sont des éléments brandis par les habitants de Port-Saïd quand ils expliquent leur choix, le facteur religieux est quant à lui plus discrètement abordé. Interrogés sur les trois principales listes de partis libéraux, trois discours sont tenus par les électeurs, expliquant leurs faibles scores :

Concernant la coalition «la Révolution continue », elle serait trop «jeune », trop mal organisée, et souffre de la mauvaise perception des échauffourées entre les manifestants et l'armée.

Concernant le Wafd, il lui est le plus souvent reproché de s'être compromis avec l'ancien régime et de faire partie des fulûl ${ }^{3}$. Son relatif bon score serait, selon des habitants interrogés, à mettre au compte de sa clientèle et de l'alternative qu'il représente au courant de l'islam politique.

Concernant le Bloc égyptien il fut, tout au long de la campagne électorale précédant le premier tour, victime d'une perception négative dont il n'est pas arrivé à se défaire. Ainsi le nom de Nagîb Sâwîris, homme d'affaires copte, fondateur et financier des Égyptiens libres, revenait de façon constante dans les conversations des habitants. Ceux-ci, suite à une polémique causée par un tweet humoristique, lui reprochent d'être hostile à l'islam. L'opposition idéologique du Bloc égyptien aux partis islamistes a été perçue comme étant une opposition confessionnelle. De nombreux habitants de PortSaïd, hommes et femmes, ont témoigné de discours tenus par certains imams lors des prêches du vendredi, appelant à ne pas voter pour le Bloc et pour Georges Ishâq car se serait « harâm » et car un bon musulman doit être solidaire avec les membres de sa communauté. Ainsi Rîhâm Sulayman des Égyptiens libres, relatait l'anecdote suivante :

«mon mari était dans une mosquée pour la prière du Vendredi et il a entendu le Cheikh dire aux fidèles lors du prêche de ne pas voter pour les Égyptiens libres car nous sommes un parti copte, et de ne surtout pas voter en faveur d'une femme qui s'affiche sans voile!»

Pour les candidats du Bloc égyptien, se dédouaner de toute accusation d'impiété ou de confessionnalisme était presque devenu un réflexe. Ainsi à la question « Pourquoi êtesvous candidat de ce parti? Quelqu'un vous a-t-il convaincu de vous présenter aux élections avec les Égyptiens libres ? ", Girgis Grîs répondait :

«c'est nous qui volontairement nous sommes entendus pour représenter le parti à Port-Saïd. Nous avons la conviction que ce parti est le seul qui propose d'allier patriotisme, démocratisation et efficacité gouvernementale.

Et puis, toutes les religions ont la même base morale, ce parti n'est pas contre l'islam ou contre la religion en général. Nous sommes pour la préservation $d u$ deuxième article de la Constitution »

Les candidats du Bloc égyptien ont aussi dénoncé l'utilisation par les partis islamistes de la religion comme argument de campagne : 
«nous dénonçons la non-application des décisions de la Haute Commission des Élections concernant l'interdiction d'utiliser la religion dans le discours politique et comme slogan. Ici même, à Port-Saïd, des affiches arborent en grand « l'islam est la solution». Aussi nous faisons face à une simplification et à un dénigrement $d u$ terme libéral »

Le rôle de la religion dans ces élections se manifeste également par la méfiance affichée par de nombreuses femmes à l'égard des islamistes. Si la large victoire de ces derniers ne permet pas de parler d'un rejet massif de la part des femmes, l'on observe néanmoins une crispation de celles d'entre elles qui ne votent pas islamistes. Une femme voulant en convaincre une autre de ne pas voter salafiste utilisera des arguments portant sur les droits des femmes; droit de ne pas porter le voile ou le niqâb, droit au travail, égalité entre l'homme et la femme au sein du mariage, droit de divorce :

«Les salafistes veulent imposer le niqâb aux musulmanes et même le voile aux coptes! Tu te rends compte !»

Ce discours peut également s'adresser à l'occasion aux hommes :

"Ah bon tu vas voter salafiste? Tu n'aimes donc pas les femmes?»

Les signes de ce phénomène sont nombreux, cependant sa portée reste à évaluer. Les femmes acceptent, et même pour la plupart, soutiennent le discours islamiste sur la place de la femme dans la société. Cependant, une immixtion directe dans l'équilibre de leurs ménages ou dans leurs rapports avec les hommes en général serait, d'après elles, une déclaration de guerre. Une femme portant le voile intégral affirmait ainsi :

«Je veux que ma fille puisse se marier ! Je ne voterai pas pour les islamistes »

Alors qu'une autre, exaspérée, relatait l'anecdote suivante :

«Un marchand, alors que je réglais mes courses, m'as scruté de haut en bas puis -

alors que je suis voilée !- m'a tendu un petit livre sur la femme en Islam »

\section{Conclusion}

3 Au-delà des insaisissables logiques personnelles, se sont bien la réputation, la proximité et la piété ou même la confession des candidats qui ont déterminé le vote des habitants de la ville. Ces critères, mis en avant par les habitants durant la campagne, peuvent être jusqu'à un certain point systématisés pour expliquer les raisons du succès de certains et de la défaite d'autres.

4 Le résultat des élections législatives a surpris beaucoup d'habitants de Port-Saïd. Beaucoup ont confié avoir le sentiment d'avoir étés trop mobilisés contre les libéraux, notamment contre Georges Ishâq. Les habitants s'attendaient à un deuxième tour entre lui et Akram al-Chầr. Ils ont avoué avoir fait barrage à un candidat qui s'est révélé avoir une plus faible assise électorale qu'ils se l'imaginaient.

Si le thème de l'inaction des anciens députés Frères musulmans, lancé par les libéraux, n'a pas pris durant la campagne, les habitants ne pardonneront pas aux islamistes l'absence d'avancées sociales visibles lors de prochaines élections. Cet avertissement, de nombreuses fois entendu, vaut également pour les salafistes dont les électeurs attendent un discours ou des actions de transformation radicale sans compromission avec les modérés, et au profit des plus musulmans d'entre eux. 
L'affiche du parti Al-Nûr a fait rire ses opposants et embarrassé ses partisans. Exposer sa barbe aux quatre coins de la ville ne serait pas ce que l'on attend d'un salafiste.

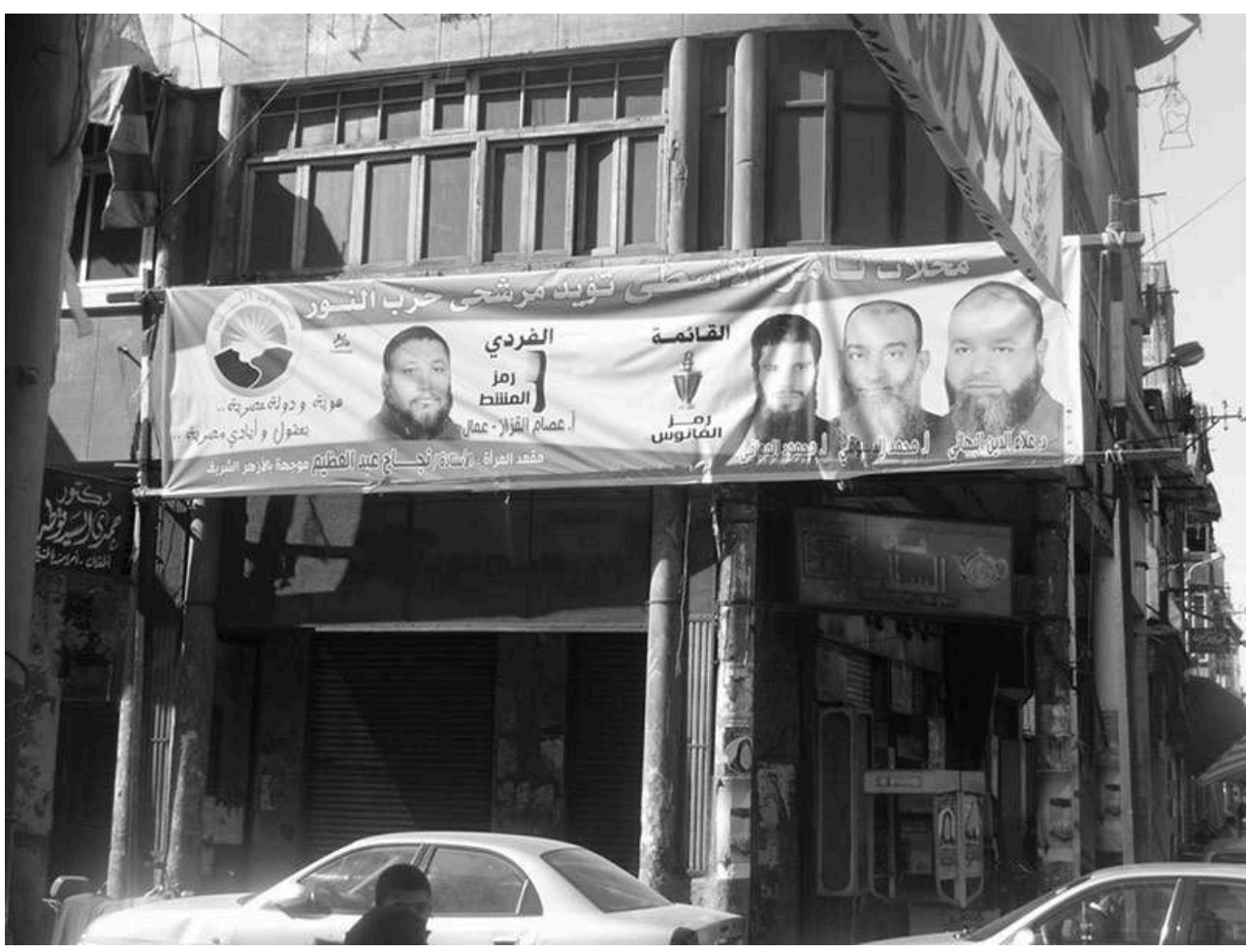

\section{NOTES}

1. Le 14 décembre 2004, l'Égypte a signé un protocole avec Israël et les États-Unis portant sur les zones industrielles qualifiées (QUIZ). Ce protocole favorise l'accès des produits égyptiens sur les marchés américains sans taxes douanières ni quotas déterminés, à condition que le composant israélien ne dépasse pas les $11,7 \%$. La première étape, au gouvernorat de Port-Saïd, commence par 22 usines qualifiées et un volume d'exportation dépassant 59 millions de dollars et une main-d'œuvre évaluée à 26000 ouvriers. http://www.sis.gov.eg/Fr/Story.aspx?sid=660

2. Le maréchal Muhammad Husayn Tantâwî était alrs le chef du Conseil supérieur des forces armées qui fut à la tête du pouvoir exécutif jusqu'aux élections présidentielles de 2012.

3. Cadres de l'ancien régime de Moubarak. Voir le lexique en fin de volume. 


\section{RÉSUMÉS}

Rédigé en novembre 2011 dans le cadre de l'étude par le CEDEJ du déroulement des premières élections législatives post-révolutionnaires en Égypte, cet article s'appuie sur la rencontre avec des personnalités politiques de Port-Saïd, et sur des impressions recueillies auprès des habitants de la ville pour comprendre quels ont été les enjeux et problématiques qui ont influé sur les résultats électoraux de la circonscription. Il en résulte que ce sont les réputations de moralité des candidats, ainsi que les problématiques locales et la religion qui ont déterminé le vote des habitants de Port-Saïd et marqué la campagne électorale.

Drafted in November 2011, part of the CEDEJ study of the first parliamentary election in Egypt after the Revolution, this article emphasizes on interviews with candidates of the Port Said district, and on impression and remarks of the inhabitants of the city to understand what were the stakes and the problems which influenced the results of the election. As a result, it is the reputations of morality of the candidates, as well as local issues and religion that determined the vote of the inhabitants of Port Said and dominated during the election campaign.

\section{INDEX}

Mots-clés : élections, Port-Saïd, 2011, Parlement, Frères musulman

Keywords : Elections, Port Said, 2011, Parliament, Muslim Brotherhood

\section{AUTEUR}

\section{FAYÇAL HOMSY}

Fayçal Homsy a été stagiaire, assistant du directeur du CEDEJ, de septembre 2011 à janvier 2012. Il est diplômé en Affaires Publiques de Sciences Po Paris et de l'INALCO.

Fayçal Homsy was an intern, assistant to the director of the CEDEJ from September 2011 to January 2012. He has a master in Public Management from Sciences Po Paris. 